\title{
TISSUE SPECIFIC ESTERASE EXPRESSION IN INDIGENOUS CHICKEN OF BANGLADESH
}

\author{
R. M. Shahjahan ${ }^{1}$, K. A. Muid ${ }^{1}$, Q. S. Akter ${ }^{2}$, K. M. A. Tareq ${ }^{2}$, R. A. Begum ${ }^{1}$, \\ R. Begum ${ }^{1}$ and M. A. M. Y. Khandoker ${ }^{2 *}$
}

\begin{abstract}
The present investigation was done in the esterase gene expression analysis of the Red Jungle fowl Gallus gallus of Bangladesh utilizing the polyacrylamide gel electrophoresis (PAGE) technique. Each allele produces a biochemical message that helps to produce various protein phenotypes those were expressed in the form of bands on the polyacrylamide gel bed. Altogether four different esterase bands were recorded in both Red Jungle (RJ) fowl and Naked Neck (NN) fowl of Bangladesh. These were denoted as Est-1 (2), Est-2(1), Est-3 (21) and Est-4 (13) based on the relative mobility on the gel. Among them Est-2 is very common in almost all tissues. Comparing the esterase in both genetic groups, their expression intensity even the relative mobility provided a unique feature that they were similar. The investigation indicates that esterase gene between the Red Jungle fowl and Naked Neck fowl of Bangladesh has a close relationship.
\end{abstract}

Key words: Esterase, Gel electrophoresis, Naked Neck fowl, Red Jungle fowl

\section{Introduction}

The genetic characterization of different types of native domestic animal/poultry in Bangladesh based on various isozymes are not yet studied in Bangladesh. Isozymes are multiple forms of a single enzyme, which often have different isoelectric points and therefore can be separated by electrophoresis. Electrophoretic studies were done extensively on the different tissues of various animals from which it reveals that the enzyme exit in multi molecular forms and functions (Markert and Moller, 1959). The electrophoretic banding patterns of esterases of different tissues show species-specific variation. Esterase isozymes are one of the lipid-hydrolyzing enzymes, possess high significance in genetics and toxicology (Callaghan et al., 1994 and Markert and Moller, 1959). The banding pattern of esterases appears to be genetically controlled and therefore it has been used estimate the genetic distance among different populations or the distance between populations (Turner, 1973). Esterases are also used as bioindicators to measure the toxic potency of pesticide residues usually applied in

${ }^{1}$ Laboratory of Animal Genetics and Molecular Biology, Department of Zoology, University of Dhaka, Dhaka-1000, Bangladesh

2 Reproductive Biotechnology Laboratory, Department of Animal Breeding and Genetics, Bangladesh Agricultural University, Mymensingh-2202, Bangladesh

(Received : August 8, 2009) 
agriculture (Alpuche-Gual and Gold-Bouchot, 2008). Esterases have also been extensively studied in different insects and vertebrates and for different physiological processes, such as regulation of hormone level, reproduction, functioning of nervous system (Holmes and Whitt, 1970 and Brestkin et al., 1975).

Esterase isozymes are one of the lipid-hydrolyzing enzymes; possess high significance in genetics. The banding pattern of esterases appears to be genetically controlled and therefore it has been used to estimate the genetic distance among different populations or the distance between populations. Esterases are also used as bioindicators to measure the toxic potency of pesticide residues. (Debnath, 1978). Considering the above facts, it is essential to understand the genetic status in terms of esterase variability. The esterase variability and its tissue specific expression were not observed in RJ fowl before in Bangladesh. Considering the above facts, it is essential to understand the genetic status of Red Jungle (RJ) fowl of Bangladesh in terms of esterase variability.

\section{Materials and Methods}

\section{Sample collection}

The whole carcass of the RJ fowl was collected from Bandarban District of Bangladesh. According to the requirement the tissue of forebrain, midbrain, hindbrain, heart, liver, testis, oesophagus, gizzard, crop, proventiculous, small intestine, large intestine, pectoral muscle, pelvic muscle, lung, eye, kidney, pancreas, body muscle and blood were collected. Separate special sterile bags were used for carrying the samples to avoid the contamination. The samples were then transported to the laboratory in an insulated box with ice to maintain the temperature around $4-6^{\circ} \mathrm{C}$. In the laboratory, each and every sample was taken separately and kept in deep freezer at $-80^{\circ} \mathrm{C}$ until further processing.

\section{Preparation of the sample}

Different tissues of the RJ fowl were taken in a measure nearly about $0.0159 \mathrm{gm}$. Each sample was taken to an eppendrof tube and squashed in 1X Tris-Borate EDTA buffer adding about $40 \mathrm{ml}$. After squashing $2 \mathrm{X}$ Bromophenol blue solution was added to each sample as the amount of $10 \mathrm{ml}$. The samples were then centrifuged at $12600 \mathrm{rpm}$ for 15 minutes at $25^{\circ} \mathrm{C}$. Ten $\mathrm{ml}$ of supernatant was used in each slot of the gel.

\section{Preparation of gel}

Seven and half percent (7.5\%) gel was prepared using $7.5 \mathrm{ml}$ of Acrylamidebisacrylamide (30:0.8; Bio Basic Inc); $6.0 \mathrm{ml}$ of $5 \mathrm{X}$ of TBE buffer; $0.15 \mathrm{ml}$ of $10 \%$ ammonium persulphate (AMPS; Fulka Biochemica); $0.14 \mathrm{ml}$ of TEMED and $16 \mathrm{ml}$ of sterilized distilled water. 


\section{Electrophoresis of gel}

The gel was run at $120 \mathrm{~V}$ constant voltage for at least $1 \mathrm{hr} 20 \mathrm{~min}$, until the tracking dye (bromophenol blue) reached to the bottom of gel. The gel was recovered by dismantling the glass plates sinking in water very cautiously. The gel was taken in a staining tray and $30 \mathrm{ml}$ of substrate mixture poured on to it for $15 \mathrm{~min}$ at room temperate. After 15 min, the substrate mixture was out poured and $30 \mathrm{ml}$ of fast blue RR solution added to the gel and incubated at $37^{\circ} \mathrm{C}$ for $25 \mathrm{~min}$. Photograph of the gel was taken by a digital zoom lens camera laying the gel on a white back ground (Samsung Kenox-SHD lens, 3.2 mega pixels).

\section{Scoring of bands}

Bands were scored on the stained gel from the highest to the lowest mobility and numbered accordingly (Webb 1964). Relative mobilities were estimated towards the commonly found band Est-2 as the band for unity.

\section{Polyacrylamide gel electrophoresic analysis}

Polyacrylamide gel electrophoresis (PAGE) was carried out to analyze the esterase isozyme pattern in different tissues of RJ fowl of Bangladesh. Esterases were identified in the gels by using $\alpha$ and $\beta$ - naphthyl acetate as substrates following the technique described by Johnson and Denniston (1964) and Steincr and Joslyn (1979). When only $\alpha$-naphthyl acetate was hydrolyzed, the bands in the gels turned black and named as $\alpha$ esterases and with only $\beta$ - naphthyl acetate, the bands were red and named $\beta$ esterases. Tissue specific expression of esterase isozyme was observed in the present study. Altogether four esterase bands (Est-1, Est-2, Est-3, and Est-4) were found in RJ fowl with different relative mobilities. According to the Mendelian inheritance studies on these esterase loci, each of the bands corresponds to one allele (Stordeur, 1976).

\section{Statistical analysis}

Data were analyzed using the general linear models procedure with the help of Statistical Package for Social Sciences (SPSS) version 10/11.5.

\section{Results and Discussion}

Electrophoretic banding pattern showing the intensity variation of esterase isozymes in different tissues of RJ fowl (Scored from $\alpha, \beta$ stained gel) are shown in Fig. 1. Second band which denoted as 2 was most frequently observed and selected as a standard band relative mobility of other bands was determined by comparing with that standard band. The highest relative mobility value was $2.0 \pm 0.02$ and was possessed by Est-1, located near the anode (+) pole whereas Est-4 with the slowest relative mobility, valued $0.13 \pm 0.02$ and found in the cathode (-) pole. According to this relative mobility the values of Est-2 and Est-3 were $1.0 \pm 0.02,0.2 \pm 0.02$ respectively. 

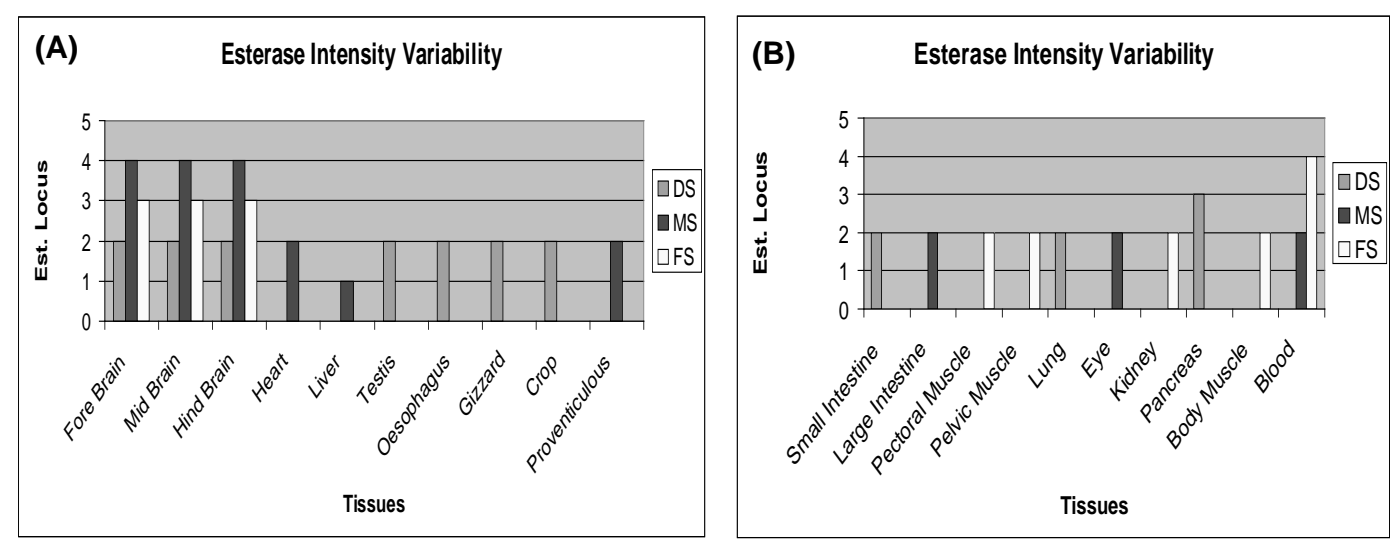

Fig. 1. Electrophoretic banding pattern showing the intensity variation of esterase isozymes in different tissues of Red Jungle fowl (Scored from $\alpha, \beta$ stained gel)

All mentioned esterase bands had tissue and substrate specific expression. Tissue specific expression of esterases was also found in sword tail fish (xiphophorus helleri) (Ahuja et al., 1977). The bands also showed an intensity variation among different tissues. Based on staining intensity, esterase isozyme bands could be arbitrarily describe in the three categories such as- (a) deep stained, (b) medium stained and (c) faint stained (Table 1). Debnath (1978) classified the intensity of esterase isozymes in to five categories among three fresh water fish species. Those were (a) very intense (b) intense (c) fairly intense (d) weak and (e) very weak.

Twenty one different esterase bands were found in Drosophila melanogaster when $\alpha$ and $\beta$ napthyl acetate were used a substrate, eighteen of them were black and thus classified as $\alpha$-esterase, two of them were red, classified as $\beta$-esterase (Taskin, 2007). But in the present investigation both $\alpha$ and $\beta$ napthyl acetate were used together.

In the present study it was observed that Est-3 and Est-4 were tightly linked. Further population study is required for this statement. Polyacrylamide gel showing esterase bands in different tissues of the RJ fowl (Scored from $\alpha, \beta$ Stained Gel) are shown in Fig. 2. Among 20 tissues observed in the present study, esterase activity was most abundant in liver, oesophagus, crop, gizzard and small intestine. Mentioned 5 organs have a relation with food digestion and metabolism of different esters e.g. fat, cholesterol etc. On the other hand, less activity observed in kidney, eye and muscles and they have a different physiological function in contrast with digestion and metabolism. High esterase activity was found in the liver and blood plasma of a range of mammalian species (Colin et al., 2004).

Since esterases have neuro-transmission activity, brain tissues are supposed to be enriched with esterases (Brestkin et al., 1975). Three esterase bands, namely Est-2, Est-3 and Est-4 were detected in the present study (Fig. 3). Many researchers observed frequently the high activity of acetylcholine esterase in the brain of different species (Brestkin et al., 1975). The maximum numbers of bands were found in the brain tissues. 
But dissimilar results were observed in fishes where liver, stomach and intestine showed the maximum number of bands (Cousin et al., 1987).

Table 1. Electrophoretic banding pattern showing the intensity variation of esterase isozymes in different tissues of $\mathrm{RJ}$ fowl (Scored from $\alpha, \beta$ stained gel)

\begin{tabular}{|rl|c|c|c|c|}
\hline Sl. No. & \multicolumn{1}{c|}{ Tissues } & Est-1 & Est-2 & Est-3 & Est-4 \\
\hline i. & Fore Brain & - & DS & FS & MS \\
ii. & Mid Brain & - & DS & FS & MS \\
iii. & Hind Brain & - & DS & FS & MS \\
iv. & Heart & - & MS & - & - \\
v. & Liver & MS & DS & - & - \\
vi. & Testis & - & DS & - & - \\
vii. & Oesophagus & - & DS & - & - \\
viii. & Gizzard & - & DS & - & - \\
ix. & Crop & - & DS & - & - \\
x. & Proventiculous & - & MS & - & - \\
xi. & Small Intestine & - & DS & - & - \\
xii. & Large Intestine & - & MS & - & - \\
xiii. & Pectoral Muscle & - & FS & - & - \\
xiv. & Pelvic Muscle & - & FS & - & - \\
xv. & Lung & - & DS & - & - \\
xvi. & Eye & - & MS & - & - \\
xvii. & Kidney & - & - & - & - \\
xviii. & Pancreas & - & - & DS & - \\
xix. & Body Muscle & - & FS & - & - \\
xx. & Blood & - & MS & MS & - \\
\hline
\end{tabular}

DS = Deep stained, MS = Medium stained, FS = Faint stained

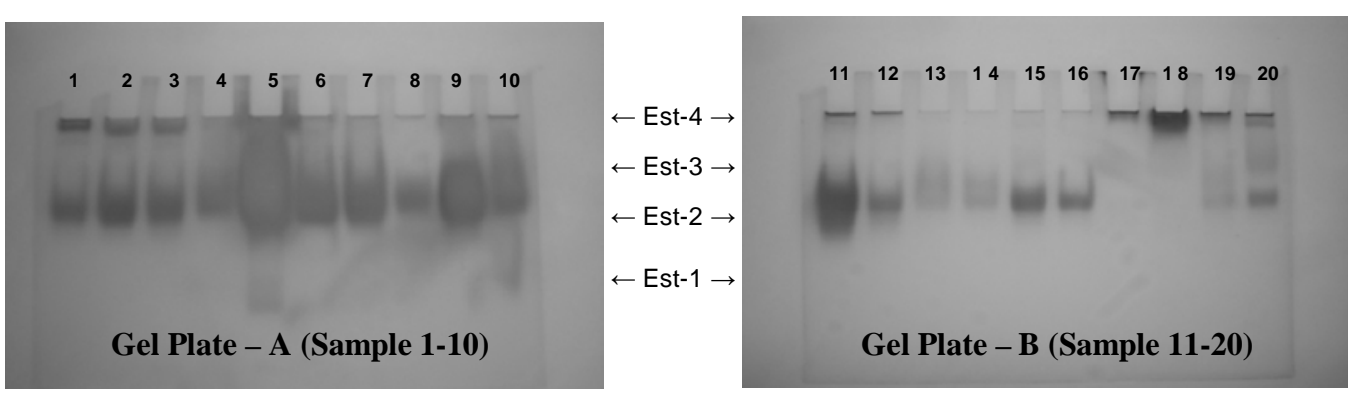

Fig. 2. Polyacrylamide gel showing esterase bands in different tissues of the Red Jungle fowl (Scored from $\alpha, \beta$ Stained Gel) 

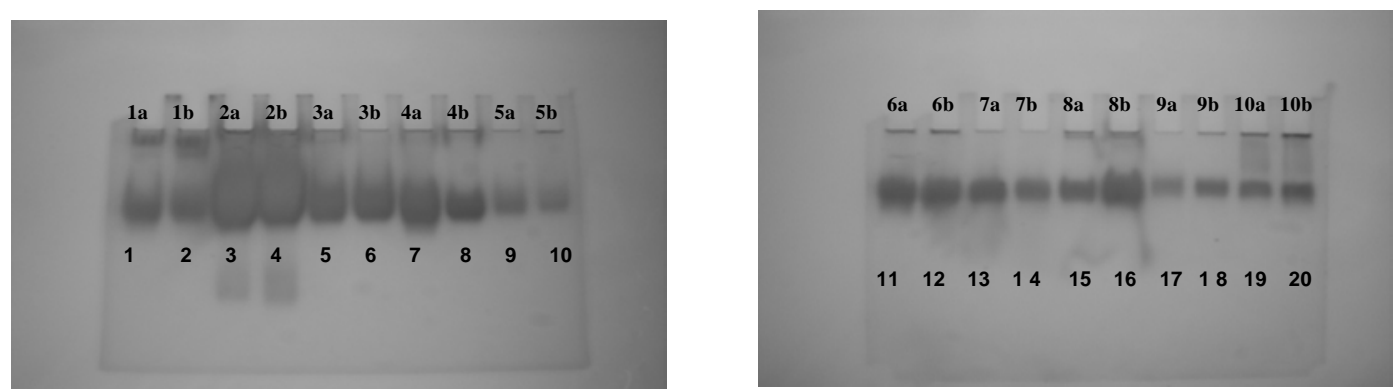

Fig. 3. Polyacrylamide gel showing esterase bands in different tissues of the Red Jungle fowl and Naked Neck fowl (Scored from $\alpha, \beta$ Stained Gel). 1-brain, 2-liver, 3-Testis, 4-Oesophagus, 5-Gizard. 6-Intestine, 7-Llung, 8-Eeye, 9-Bbody muscle, 10-Blood, $a=$ Red Jungle, $b=$ Naked Neck

As esterase activities were different in all species (Fossi et al., 1996), so banding pattern of esterases in different tissues has good potentiality for species identification (Al-amin et al., 2005). In the persent investigation, 4 esterase bands were detected in the RJ fowl of Bangladesh. Comparing the esterase banding pattern of RJ fowl with that of $\mathrm{NN}$ fowl, their esterase expression, staining intensity even the relative mobility showed an unique feature that they were similar (Table 2) which indicates that esterase gene between the RJ fowl and NN fowl in Bangladesh has a close relationship. These findings also may be a powerful tool to analyze the evolutionary and phylogenic relationship between them. Luis (1987) reported that isozymes have been used widely as tools to probe the mechanistic basis of evolutionary adaptation. In more practical application, isozymes have been used in the establishment of phylogenetic relationships among the findings in the present study may be extended to use esterase as genetic marker in various fields of physiology and taxonomy in RJ fowl.

Table 2. Banding intensity variation between red jungle and naked neck fowl

\begin{tabular}{|c|l|c|c|c|c|c|c|c|c|}
\hline \multirow{2}{*}{ SI. No. } & \multirow{2}{*}{ Tissues } & \multicolumn{2}{|c|}{ Est-1 } & \multicolumn{2}{c|}{ Est-2 } & \multicolumn{2}{c|}{ Est-3 } & \multicolumn{2}{c|}{ Est-4 } \\
\cline { 3 - 9 } & $\begin{array}{c}\text { Red } \\
\text { Jungle }\end{array}$ & $\begin{array}{c}\text { Naked } \\
\text { Neck }\end{array}$ & $\begin{array}{c}\text { Red } \\
\text { Jungle }\end{array}$ & $\begin{array}{c}\text { Naked } \\
\text { Neck }\end{array}$ & $\begin{array}{c}\text { Red } \\
\text { Jungle }\end{array}$ & $\begin{array}{c}\text { Naked } \\
\text { Neck }\end{array}$ & $\begin{array}{c}\text { Red } \\
\text { Jungle }\end{array}$ & $\begin{array}{c}\text { Naked } \\
\text { Neck }\end{array}$ \\
\hline i. & Brain & & & DS & DS & DS & MS & MS & MS \\
ii. & Liver & MS & MS & DS & DS & - & - & - & - \\
iii. & Testis & - & - & DS & DS & - & - & - & - \\
iv. & Oesophagus & - & - & DS & DS & - & - & - & - \\
v. & Gizzard & - & - & DS & MS & - & - & - & - \\
vi. & Intestine & - & - & DS & MS & - & - & - & - \\
vii. & Lung & - & - & DS & DS & - & - & - & - \\
viii. & Eye & - & - & DS & FS & - & - & - & - \\
ix. & Body Muscle & - & - & MS & FS & - & - & - & - \\
x. & Blood & - & - & DS & MS & DS & MS & - & - \\
\hline
\end{tabular}

DS = Deep stained, MS = Medium stained, $\mathrm{FS}=$ Faint stained 
Esterase expression in indigenous chicken

\section{Conclusion}

From the result it may be concluded that esterase gave between Red Jungle fowl and Naked Neck town has a close relationship and could be used in the field of genetics.

\section{Literature Cited}

Ahuja, M. R. and Schawb, F. 1977. Tissue specific esterases in the Xiphorine fish platypoecilus maculates, Xiphophorus helleri and their hybrid. Biochem. Genet. 15: 601-610.

Al-Amin, M., Sufi, G. B, and Shahjahan, R. M. 2005. Esterase isoyme pattern in Pangasius pangasius and P.sutchi. J. Biol. Sci. 14: 193-196.

Alpuche-Gual, L. and Gold-Bouchot, G. 2008. Determination of esterase activity and characterization of cholinesterases in the reef fish Haemulon plumieri. Ecotoxi. Envi. Saf. 71: 787-797.

Brestkin, A. P. and Grioria. 1975. Acetylcholin esterase from the electric organ of the ray fish Torpedo marmorata. Evol. biochem. Physiol. 11: 250-257.

Callaghan, A., Boiroux, V., Raymond, M. and Pasteur, N. 1994. Prevention of changes in electrophoretic mobility of overproduced esterase from organophosphate resistant mosquitoes of the Culex pipiens complex. Med. Veterin. Entomol. 8: 391-394.

Colin, W. 2004. 'A' esterase and their role in regulating the toxicity of organophosphates. Arch. Toxic. 60: $30-33$.

Cousin, J. C. B., Baudin-Laurencin, F. and Gabaudan, J. 1987. Ontogeny of enzymatic enzyme activities in fed and fasting turbot, (Scophthalmus maximus). L. J. Fish Biol. 30: 15-33.

Debnath, J. C. 1978. Electrophoretic and Biochemical studies of proteins and isozymes of nonspecific esterase. University Medical Centre, Sarajevo. Ph D thesis. pp-1-87.

Fossi, M. C., Lari, L. and Casini, S. 1996. Interspecific variation of 'B' esterase in birds. Arch. Envir. Conta. Toxic. 31: $525-532$.

Holmes, R. S and Whit, G. S. 1970. Developmental genetics of the esterase isozymes of Fundulus heteroclitus. Biochem. Genet. 4: 471-480.

Johnson, F. M. and Denniston, C. 1964. Genetic variation of alchohol dehydrogenase in Drosophila melanogaster. Nature, 204: 906 - 907.

Luis N. M. and Searle, D. 1987. Isozyme have been used in the establishment of phylogenetic relationships among taxa. Biochem. Genet. 25: $9-10$.

Markert, C. L. and Moller, F. 1959. Multiple forms of enzymes: Tissue, ontogenetic and species specific patterns. Proc. Natl. Acad. Sci. 45: 753-763.

Steiner, W. W. M. and Joslyn, D. J. 1979. Electrophoretic techniques for the genetic study of mosquitoes. Mosq. News. 39: 35-54.

Stordeur, D.E. 1976. Esterases in the mosquito Culex pipiens. formal geneties and polymorphism of adult esterases. Biochem. Genet. 14: 481 - 493.

Taskin, E. 2007. A summary of reports of Ulvaceae (Chlorophyta) from Turkey. Pak. J. Biol. Sci. 10: 1934-1937.

Turner, B. J. 1973. Genetic divergence of Death Valley pupfish populations. Species specific esterases. Biochem Physiol. 46: 57-70.

Webb, E. C. 1964. Nomenclature of multiple enzyme forms. Nature. 203: 821-829. 